\title{
A Local Perspective: Experiences And Handling of Mental Health Burden During The COVID-19 Pandemic In Uganda.
}

Choolwe Muzyamba ( $\nabla$ muzyamba@merit.unu.edu )

University College Utrecht

Bob Mwiinga Munyati

London School of Hygiene \& Tropical Medicine

Ogylive Makova

AfriSight

Geofrey Mushibi

AfriSight

Research article

Keywords: COVID-19, mental-health, Uganda

Posted Date: September 16th, 2021

DOI: https://doi.org/10.21203/rs.3.rs-549744/v2

License: (c) (i) This work is licensed under a Creative Commons Attribution 4.0 International License.

Read Full License 


\section{Abstract}

\section{Background}

The COVID-19 pandemic has increased the prevalence of mental health illness around the world. While research has espoused these realities from the context of western countries, however, similar evidence from low income countries like Uganda is still missing. This is despite the fact that scholars have pointed out that given inadequate funding, health facilities and personnel to treat people with mental health challenges, the impact of the COVID-19 pandemic could be severe. Further, it is still unclear how locals in low income countries like Uganda manage to cope with mental health challenges given the lack of adequate skilled response, especially during a pandemic that has increased the pressure on the healthcare system. Therefore, this study aims to fill this gap by investigating local people's experience and handling of mental health burden during the COVID-19 pandemic $\mathrm{n}$ Uganda.

\section{Methods}

Qualitative primary data was collected from Uganda in November and December 2020. The sample selection involved a two-staged cluster sampling technique via the AfriSight online platform. Our study included a total of 1249 participants picked from the 4 different regions of Uganda. On the basis of this, thematic analysis was used to analyze the data.

Results

Our study revealed that the COVID-19 pandemic and its associated interventions contributed to the increasing mental health burden in Uganda. The four most pronounced forms of mental health illnesses included stress, anxiety, depression and traumatic disorders with the leading causes being closure of income-generating activities, fear of dying, sexual and domestic abuse. While a few people had access to skilled mantel health care, the majority of the people struggled to access this form of care. Skilled maternal care remained an attractive yet unattainable form of care for many. Thus, most people relied on various forms of local strategies that were feasible.

\section{Conclusion}

Our study revealed that Uganda was home to various local survival strategies that counter the inadequacies presented by the weak health care system. Particularly, a culture of reciprocity, family and community network forms important coping avenues for many left stranded by the lack of adequate skilled care. Thus, in the context of Uganda during the COVID-19 pandemic, it seemed more logical to promote scaling up feasibly and locally-available solutions rather than idealistically focusing on attractive yet unattainable forms of care.

\section{Background}


The spread of Coronavirus Disease of 2019 (COVID-19) has led to government-imposed lockdowns across the world since April 2020. Lockdowns are essential in cutting down contact between people and reducing the virus' spread (Ferguson, et al., 2020). While aiming to reduce the spread of the COVID-19 pandemic, some scholars have pointed out that lockdowns could negatively affect society (Armitagea \& Nellumsa, 2020). Lockdowns could lead to various adverse social and economic consequences, including poor mental health, as demonstrated in multiple studies in the global north (Pierce, Hope, Ford, Hatchi, \& John, 2020). For example, studies from the United Kingdom (UK) show how mental health problems have been rising since the introduction of lockdowns sparking fears of a 'mental health epidemic' (Townsend, 2020; Pierce, Hope, Ford, Hatchi, \& John, 2020).

Further, Armitage and Nellums (2020) show that COVID-19-related lockdowns led to severe anxiety and depression, especially among marginalized groups in the UK (Armitagea \& Nellumsa, 2020; Burgess, 2020). Lockdowns curtail channels of constant social interaction, thereby leading to feelings of loneliness and social isolation, which are a good breeding ground for anxiety and depression (Armitagea \& Nellumsa, 2020). The poor mental health surge resulting from lockdown measures is not unique to the UK. Researchers in China found that suicidal ideation and self-harm increased during the lockdown among young people (Zhang, et al. 2020).

The growing scientific evidence of the effects of lockdown measures on mental health in high-income countries raises concerns about the situation in the global south countries given their already existing burden of disease (Burgess, 2020). There are suggestions that countries in the global south could soon be overwhelmed by mental health problems (Burgess, 2020). This is because low-income countries have etiological factors such as poverty, low schooling and unemployment, leading to higher mental health challenges and disorders (Pires, et al., 2019). The Dohrenwend model (which offers insights on how socioeconomic stress resulting from lockdown) suggests that poverty combined with lockdown predisposes people to financial strain and food insecurity increasing the likelihood of people developing mental health problems (Dohrenwend, 1978). Not only that, some other studies also demonstrate that most low-income cultures in Africa thrive on daily social contact and interaction. Thus the lockdown measures at such proportions present even greater risks to people in whose culture social isolation is alien (Burgess, 2020; Pires, et al., 2019). Burgess (2020) also emphasizes that the marginalized people within Africa face daunting mental health problems given the lack of socioeconomic security. Charlson 2014, predicted that due to the epidemiological and demographic transitions taking place in Sub-Saharan Africa, the prevalence of mental health challenges increases by $130 \%$ between 2010 and 2050 (Charlson, Diminic, Lund, Degenhardt, \& Whiteford, 2014). Therefore, it seems plausible that lockdowns have only worsened the situation (Burgess, 2020). Despite all this knowledge about the state and trend of mental health challenges in low-income countries, there is little focus on how lockdowns have impacted the mental health of citizens in these countries. On this account, there is a need for evidence-based research, especially in a country like Uganda that already registered high mental health challenges before the onset of the Covid-19 pandemic (Kigoz, et al., 2010; Molodynski, Cusack, \& Nixon, 2017). 
The exact extent of mental health in Uganda remains unknown, with low reporting due to various problems, including mental health-related stigma. Molodynski et al. estimate that over a third of Ugandans have a mental disorder, and 15\% require treatment. (Molodynski, Cusack, \& Nixon, 2017). Despite having a large proportion of its population with mental health problems, Uganda faces inadequate spending on health like many other low-income countries. In the 2019/2020 financial year, Uganda allocated $8.9 \%$ of its national budget to the health sector, significantly lower than the $15 \%$ Abuja Declaration recommendation (Unicef, 2019). Concerning mental health, Uganda spent between 1 and $4 \%$ of its budgeted health allocation on mental health (Kigoz, et al., 2010; Bird, et al., 2010). As a result, there are only 1.83 and 1.4 beds per 100,000 people in mental hospitals and psychiatry inpatient units, respectively. Not only is Uganda facing inadequate funding and health care facilities dedicated to mental health, but the country also has a shortage of health personnel specialized in mental health. Of all medical doctors in the country, only $0.4 \%$ had specialized in psychiatry, with nurses showing a slightly higher specialization of $4 \%$ in the same field of study (Kigoz, et al., 2010). This translates into having only 0.08 psychiatrists and 0.78 nurses working in psychiatric facilities per 100, 000 people.

There are many people at risk of experiencing or already experiencing mental health challenges in Uganda. Given inadequate funding, health facilities and personnel to treat people with mental health challenges, the impact of the lockdown could be severe. However, this requires further academic research. Further, it is still unclear how locals manage to cope with mental health challenges given the lack of adequate skilled response, especially during a pandemic that has increased the pressure on the healthcare system. Other scholars point out that most studies undermine and overlook locally based and contextually unique coping strategies to mental health in Africa (Burgess, 2020). Therefore, this study aims to fill this gap by investigating local people's experience and handling of mental health burden during the COVID-19 pandemic.

\section{Methods}

\section{Ethical clearance}

Before colleting the data, we obtained ethical clearance from the Ethics Committee of the Faculty of Law of the University of Amsterdam, the Netherlands. The Ethics Committee declared that our study complied with the ethical standards set by the committee. These standards included: 1. The Charter of Fundamental Rights of the European Union (2000/C 364/01), esp. Art. 3 (Right to the integrity of the person) and Art. 8 (Protection of personal data). 2. The Netherlands Code of Conduct for Research Integrity (VSNU, 2018). 3. The General Data Protection Regulation (GDPR), see https://www.eugdpr.org/.1. Other than that, we also obtained ethical clearance from the Ugandan local ethical clearance IRB called Makerere University School of Medicine Research and Ethics Committee (SOMREC). Further, participants were informed of the objectives of the study, assured of strict confidentiality. After that, if participants freely consented to participant, they signed a written consent form. Participants were also informed of their right to withdraw from the study at any point should they see it fit. 
Primary qualitative data was collected in Uganda in November and December 2020 by use of a crosssectional survey hosted by AfriSight platform. AfriSight is an Afrrocentric platform that collects various forms of socioeconomic data in African countries. Particularly for this survey, participants were recruited countrywide using a two-stage stratified cluster sample design. In the first stage, Uganda was divided into its 4 regions Central, Eastern, Western, and Northern resulting to 4 separate sampling strata. In the second stage, a complete list of households and their heads including contact details in each of the 4 separate strata was used to randomly select participants. Mores specifically, 500 households from each of the regions were randomly selected from the list lading to an initial sample of 2000 (500 from each region). The 500 heads of these particular households were recruited and sent the questionnaire and of this total, 1249 of them responded representing a response rate of $63 \%$. The final 1249 participants then formed the sample that was included in this study.

The data collected included demographics of participants, their knowledge of the lockdown, experience with the lockdown, mental health challenges resulting from the lockdown, and their coping strategies. The data collected was informed by various forms of research on mental health (Bird, et al., 2010; Charlson, Diminic, Lund, Degenhardt, \& Whiteford, 2014; Kigoz, et al., 2010; Pierce, Hope, Ford, Hatchi, \& John, 2020; Pires, et al., 2019). See table 1 for the demographics of our participants:

\section{Data Analysis}

Data was analyzed using thematic analysis strategy in NVivo. This was done inductively. Particularly, codes of similar sentiments by respondents were grouped together to give raise to sub-themes. By correlating and grouping together of resulting sub-themes, we built global themes that were divided into two general categories namely experience with mental health, and local coping strategies. See table 2 for the summary of results.

\section{Results}

As can be seen from table 2, our participants reported having experienced various forms of mental health challenges during the pandemic. The most reported forms included stress, depression, anxiety, and traumatic disorders. These conditions were caused by various issues including but not limited to loss of jobs, closing down of businesses and other sources of income, closing down of educational institutions, shortage of food, sexual and domestic abuse, fear of contracting the virus, brutality from the state, and death of close people. This can be highlighted sentiments by our participants as shown below:

"Lockdown has increased poverty in families because people have not been working, increased teenage pregnancies because children are not in school and high crime rate among the youth since they have not been working" 
"It allowed to a state of uncalled for general public panic and illogical restrictions which tend to be enforced with brutality in a country such as Uganda"

"Loss of jobs among youths and people and that led unemployment"

"Due to the lockdown many companies reduced their workers hence making many jobless"

"It caused drastic poverty that the poor people could hardly afford their basic needs"

More than that, our respondents highlighted the relevant government initiatives and avenues that were useful for them in navigating the various mental health challenges. They stated how the availability of counselors and dedicated healthcare workers was useful in averting some of the anxieties that they faced. Despite the availability of such an option, they however remained critical of the inadequacy of such services.

"Credit to health workers who have managed to deal with most of these challenges even under very difficult circumstances"

"That's around 2 months so it can be enough for the ministry of health to find a way out but that time frame must be on condition that the government helps us with some things mainly food coz times are really tough here"

"There is not enough healthcare workers to respond to both the mental health pandemic and the COVID19 pandemic"

Despite the above institutional challenges, our respondents talked about the various locally based and communal strategies worked to counter the institutional inadequacies. Participants stressed that community and family networks played key roles in helping them handle the various mental health challenges presented by the pandemic. Family and community members provided various forms of assistance ranging from provision of food, income and other forms of resources, much-needed company, and motivation to keep going. Participants stated that within the Ugandan cultural fabric, community and family networks were strong pillars of survival and sustenance in difficult circumstances. The value of these networks was heavily embedded in the day to day lives of people to the extent that it created reciprocal responsibilities to provide for each other in times of need. As a result of this, most participants found much needed relief from the otherwise devasting effects of the pandemic on their mental health.

"I think lockdowns bring us together as a family or community"

"I relied a lot on my family after I lost my job and was anxious and depressed, they helped me a lot and I think many people in my situation probably faced the same"

"Our culture demands that we help those in needs, and this lockdown helped us apricate that more because people really stood up for each other." 


\section{Discussion}

Our findings bring to light the prevalence of mental health challenges which have been exacerbated by the pandemic and the associated responses in Uganda. The most reported forms of mental health illness include anxiety, stress, depression and traumatic disorders. The lockdown in Uganda was linked to various risk factors responsible for the increased burden of mental health experienced by the locals. Particularly, the lockdown-precipitated job loses, food shortages, and loss of personal freedoms significantly contributed to high prevalence of mental health illnesses. Not only that, closing down of businesses and other sources of income, educational disruptions, sexual and domestic abuse, fear of contracting the virus, brutality from the state, and death of close family members and friends were also among the highlighted factors leading to the mental health challenges.

In the context of Uganda, it seems plausible that the various channels of livelihoods which were curtailed by the lockdown presented unique challenges to individuals and families who felt threatened by consequences of the lockdown and the COVID-19 pandemic itself. Prevalence of mental health illnesses skyrocketed all over Sub-Saharan Africa during the pandemic pointing to the lack of cushioning government subsidies to protect citizens from the damaging effects of the pandemic (Charlson, Diminic, Lund, Degenhardt, \& Whiteford, 2014; Posel, Oyenubi, \& Kollamparambil, 2021). Some studies have pointed out that the impact of lockdowns on mental health is worse in low-income countries like Uganda because the act of closing down channels of daily survival presents a threat of imminent deaths from hunger to most families (Lirri, 2020; Kigoz, et al., 2010). The majority of Uganda's labor force is dominated by the informal sector, meaning that people survive hand-to-mouth with many of them lacking savings or insurance covers (Lirri, 2020). Threats presented by the lockdown that directly cut their sources of livelihood without the possibility of government bailouts puts extra pressure on their mental health. All this is inline with what other studies have demonstrated in other parts of Africa (Posel, Oyenubi, \& Kollamparambil, 2021).

While some respondents had access to counselors to help them through their illnesses, many of them bemoaned the inefficient and failing healthcare system-which in most cases failed to satisfy their needs. Various studies have already shown the difficulties associated with accessing skilled mental health care in Uganda (Bird, et al., 2010; Molodynski, Cusack, \& Nixon, 2017). Thus, while it is logical to recommend (as most policy prescriptions do) scaling up of mental health care facilities, such prescriptions remain attractive yet attainable options for most people in Uganda (Kigoz, et al., 2010). The government in Uganda faced many challenges including handling a huge burden of various communicable illnesses such as malaria, tuberculosis, and HIV. This burden already puts unbearable pressure on all the existing weak healthcare system (Molodynski, Cusack, \& Nixon, 2017). This means that illnesses bordering on mental health are far from being top priority within the continuum of care in Uganda. It is as Muzyamba et al (2018) have pointed out, which is that most prescriptions centered on solely scaling up of skilled 
care in African settings are counterproductive, blunt and out of context endeavors (Muzyamba, Groot, Pavlova, \& Tomin, 2017; Muzyamba, Groot, Tomini, \& Pavlova, 2018).

Concomitant to our findings, it is worth noting that despite the institutional failings in addressing mental health in Uganda, there exists various local survival strategies that are worth highlighting (Wakida, et al., 2018). Particularly, our respondents emphasized the role of family and community networks that serve as coping avenues in the absence of skilled care. Most respondents who experience mental health challenges benefited from peer support in various forms from family and community members. This speaks to the less-pronounced benefits of local survival strategies that are usually overlooked in pursuant of attractive yet unattainable 'western-style' forms of care (Wakida, et al., 2018; Kim, Nyengerai, \& Mendenhall, 2020). The various forms of assistance rendered to mental health patients in form of food, shelter, company and motivation are important in the continuum of mental health care. Burges (2020) cautioned that the lack of appreciation of such feasible local modes of care in low-income countries is a lost opportunity (Burgess, 2020). Particularly, she points out that "without food, shelter and safety, there can be little hope for sustaining good mental health during or after this crisis". This solidifies the arguments that many scholars have been putting forward for years now, which is that it is important to scale up feasibly and locally-available solutions rather than idealistically focusing on attractive yet unattainable forms of care (Muzyamba, Groot, Tomini, \& Pavlova, 2018; Wakida, et al., 2018).

\section{Limitations}

Due to various barriers presented by lockdown measures, we conducted our data collection via online platforms. This meant that only those with access to WiFi were able to participate in the study thereby affecting the representativeness of our sample. However, despite all this, we argue that our findings provide novel insights on how the COVID-pandemic and its associated interventions have affected the mental health Ugandans and also highlights the available coping strategies in the face of a weak health care system.

\section{Conclusions}

Our study revealed that the COVID-19 pandemic and its associated interventions contributed to the increasing mental health-illness prevalence in Uganda. The four most pronounced forms of mental health illnesses included stress, anxiety, depression and traumatic disorders with the leading causes being closure of income-generating activities, fear of dying, sexual and domestic abuse. While a few people had access to skilled mantel health care, the majority of the people struggled to access this form of care. Skilled maternal care was an attractive yet attainable form of care for many in Uganda. Despite this challenge, our study reveals that Uganda is home to various local survival strategies that counter the inadequacies presented by the weak health care system. Particularly, a culture of reciprocity, family and community network form important coping avenues for many left stranded by the lack of adequate skilled care. Thus, in the context of Uganda during the COVID-19 pandemic, it seemed more logical to 
promote scaling up feasibly and locally-available solutions rather than idealistically focusing on attractive yet unattainable forms of care.

\section{Abbreviations}

COVID-19: Coronavirus Disease of 2019

GDPR: General Data Protection Regulation

HIV: Human Immunodeficiency Virus

SOMREC: Makerere University School of Medicine Research and Ethics Committee

SBIR: Small Business Innovation Research

WHO: World Health Organization

\section{Declarations}

\section{Ethics approval and consent to participate}

Before colleting the data, we obtained ethical clearance from the Ethics Committee of the Faculty of Law of the University of Amsterdam, the Netherlands. The Ethics Committee declared that our study complied with the ethical standards set by the committee. These standards included: 1 . The Charter of Fundamental Rights of the European Union (2000/C 364/01), esp. Art. 3 (Right to the integrity of the person) and Art. 8 (Protection of personal data). 2. The Netherlands Code of Conduct for Research Integrity (VSNU, 2018). 3. The General Data Protection Regulation (GDPR), see https://www.eugdpr.org/.1. Other than that, we also obtained ethical clearance from the Ugandan local ethical clearance IRB called Makerere University School of Medicine Research and Ethics Committee (SOMREC). Further, participants were informed of the objectives of the study, assured of strict confidentiality. After that, if participants freely consented to participant, they signed a written consent form. Participants were also informed of their right to withdraw from the study at any point should they see it fit.

\section{Consent for publication}

Not applicable.

\section{Availability of data and materials}

All materials relating to this study are provided

\section{Competing interests}

The author declares no competing interests 


\section{Funding}

The study was funded by AfriSight and the Small Business Innovation Research (SBIR) - RVO.nl

\section{Authors' contributions}

CM provided leadership on all aspects of the study, while CM, BM, GM, and OM also effectively contributed in carrying out the study including drafting the manuscript. All the authors read and approved the final manuscript.

\section{Acknowledgements}

Afrisight is doing a project in an innovation competition (SBIR) funded by the Ministry of Foreign Affairs of the Kingdom of the Netherlands. Through this competition, Afrisight is able to develop a digital platform to collect reliable data during lockdowns. The data collected by the digital platform can be used for advocacy and awareness campaigns. They provide information on how governments and companies can take measures to address the concerns of their citizens.

\section{References}

1. Townsend E. (2020). COVID-19 policies in the UK and consequences for mental health. Lancet, 7(12). doi:https://doi.org/10.1016/S2215-0366(20)30457-0.

2. Pierce M, Hope H, Ford T, Hatchi S, John A. (2020). Mental health before and during the COVID-19 pandemic: a longitudinal probability sample survey of the UK population. Lancet Psychiatry, 883892. Retrieved from https://www.thelancet.com/journals/lanpsy/article/PIIS2215-0366(20)303084/fulltext.

3. Zhang L, Zhang D, Fang J, Wan Y, Tao F, Sun Y. (2020). Assessment of mental health of Chinese primary school students before and after school closing and opening during the COVID-19 pandemic. jama network open, 3(9). doi:10.1001/jamanetworkopen.2020.21482.

4. Armitagea R, Nellumsa LB. COVID-19 and the consequences of isolating the elderly. Lancet Public Health. 2020. doi:10.1016/S2468-2667(20)30061-X.

5. Burgess R. (2020). COVID-19 mental-health responses neglect social realities. Nature. Retrieved from https://www.nature.com/articles/d41586-020-01313-9?fbclid=IwAR2McioEltHhZk_alZA0pb72T0YGdJAQrdCIKFY26Hao6cNRrMGeuueQDk.

6. Charlson FJ, Diminic S, Lund C, Degenhardt L, Whiteford HA. (2014). Mental and Substance Use Disorders in Sub-Saharan Africa: Predictions of Epidemiological Changes and Mental Health Workforce Requirements for the Next 40 Years. Plos one.

7. Pires P, Belo A, Anube A, Santos D, Arroz J, Pereira J,.. . Escobar S. (2019). Mental health in Mozambique; a systematic review. International Journal of Family \& Community Medicine.

8. Molodynski A, Cusack C, Nixon J. (2017). Mental healthcare in Uganda: desperate challenges but real opportunities. BJPsych International, 14(4)(98-100). Retrieved from 
https://www.ncbi.nlm.nih.gov/pmc/articles/PMC5663025/.

9. Unicef. (2019). The National budget framework FY 2019/20. Retrieved from

https://www.unicef.org/esa/sites/unicef.org.esa/files/2019-04/UNICEF-Uganda-2019-Health-BudgetBrief.pdf.

10. Kigoz F, Ssebunnya J, Kizza D, Cooper S, Ndyanabangi S. \& The Mental Health and Poverty Project. (2010). An overview of Uganda's mental health care system: results from an assessment using the world health organization's assessment instrument for mental health systems (WHO - AIMS). International Journal of Mental Health Systems, 4(1). Retrieved from http://www.ijmhs.com/content/4/1/1.

11. Bird P, Omar M, Doku V, Lund C, Nsereko RJ, Mwanza J. \& The MHaPP Research Programme Consortium. (2010). Increasing the priority of mental health in Africa: findings from qualitative research in Ghana, South Africa, Uganda and Zambia. 26(5), 357-365. Retrieved from https://doi.org/10.1093/heapol/czq078.

12. Xiao Y, Torok ME. (2020). Taking the right measures to control COVID-19. The Lancent. Retrieved from https://www.thelancet.com/pdfs/journals/laninf/PIIS1473-3099(20)30152-3.pdf.

13. Ferguson NM, Laydon D, Nedjati-Gilani G, Imai N, Ainslie K, Baguelin M,.. . Ilaria. (2020). Report 9: Impact of non-pharmaceutical interventions (NPIs) to. London: Imperial College COVID-19 Response Team. Retrieved from https://www.imperial.ac.uk/media/imperial-college/medicine/sph/ide/gidafellowships/Imperial-College-COVID19-NPI-modelling-16-03-2020.pdf.

14. Dohrenwend BS. Social stress and community psychology. American Journal of Community Psychology volume. 1978;6:1-14. doi:https://doi.org/10.1007/BF00890095.

15. Posel D, Oyenubi A, Kollamparambil U. (2021). Job loss and mental health during the COVID-19 lockdown: Evidence from South Africa. PLose One, 16(3). doi:10.1371/journal.pone.0249352.

16. Lirri E. (2020). How Uganda's tough approach to Covid-19 is hurting its citizens. Kampala: The Telegraph. Retrieved from https://www.telegraph.co.uk/global-health/science-and-disease/ugandastough-approach-covid-19-hurting-citizens/.

17. Kim AW, Nyengerai T, Mendenhall E. (2020). Evaluating the Mental Health Impacts of the COVID-19 Pandemic in Urban South Africa: Perceived Risk of COVID-19 Infection and Childhood Trauma Predict Adult Depressive Symptoms. Psychological medicne, 1-13. doi:10.1017/S0033291720003414.

18. Muzyamba C, Groot W, Pavlova M, Tomin S. (2017). The usefulness of traditional birth attendants to women living with HIV in resource-poor settings: the case of Mfuwe, Zambia. BMC Tropical Medicine Health, 45(37). doi:10.1186/s41182-017-0076-3.

19. Muzyamba C, Groot W, Tomini S, Pavlova M. (2018). Community mobilization and maternal Care of Women Living with HIV in poor settings: the case of Mfuwe, Zambia. BMC Health Services, 18(155). doi:10.1186/s12913-018-2959-3.

20. Wakida EK, Obua C, Rukundo GZ, Maling S, Talib ZM, Okello ES. (2018). Barriers and facilitators to the integration of mental health services into primary healthcare: a qualitative study among Ugandan 
primary care providers using the COM-B framework. BMC Health Services Research, 18(890). doi:10.1186/s12913-018-3684-7.

\section{Tables}

Table 1. Summary results

\begin{tabular}{|c|c|c|c|c|}
\hline Variable & observations & Variable levels & Frequency & $\begin{array}{l}\text { Percentage of total } \\
(\%)\end{array}$ \\
\hline \multirow[t]{2}{*}{ Gender } & \multirow[t]{2}{*}{1242} & Male & 691 & 55.64 \\
\hline & & Female & 551 & 44.36 \\
\hline \multirow[t]{4}{*}{ Marital status } & \multirow[t]{4}{*}{1242} & Single & 858 & 69.08 \\
\hline & & Married & 366 & 29.47 \\
\hline & & Divorced separated & 14 & 1.13 \\
\hline & & Widowed & 4 & 0.32 \\
\hline \multirow[t]{2}{*}{ Are you religious? } & \multirow[t]{2}{*}{1094} & Yes & 1068 & 97.62 \\
\hline & & No & 26 & 2.38 \\
\hline \multirow{3}{*}{$\begin{array}{l}\text { Religious } \\
\text { affiliation }\end{array}$} & \multirow[t]{3}{*}{1074} & Christianity & 945 & 87.99 \\
\hline & & Islam & 102 & 9.50 \\
\hline & & Other & 27 & 2.51 \\
\hline \multirow[t]{3}{*}{ Education level } & \multirow[t]{3}{*}{1242} & $\begin{array}{l}\text { Primary education \& } \\
\text { below }\end{array}$ & 4 & 0.32 \\
\hline & & Secondary education & 299 & 24.07 \\
\hline & & Higher education & 939 & 74.65 \\
\hline \multirow[t]{3}{*}{ Source of income } & \multirow[t]{3}{*}{1242} & Employed & 383 & 30.84 \\
\hline & & Running own business & 354 & 28.50 \\
\hline & & Unemployed & 505 & 40.66 \\
\hline \multirow[t]{3}{*}{ Income per month } & \multirow[t]{3}{*}{1242} & Below 430, 000 Shillings & 843 & 67.87 \\
\hline & & $\begin{array}{l}\text { Between 430, 000-762, } \\
000\end{array}$ & 240 & 19.32 \\
\hline & & Above 762,100 Shillings & 159 & 12.80 \\
\hline
\end{tabular}


Table 2

summary of qualitative results

\begin{tabular}{|ll|}
\hline Global Theme & Codes \\
\hline Types and sources of mental health disorders & \\
& \\
& - Types : \\
& - Stress \\
& - Depression \\
& - Anxiety \\
& - traumatic disorders \\
& - Lauses: \\
& - Shortage of food \\
& - Loss of income \\
& - sexual and domestic abuse \\
& - fear of contracting the virus \\
& - brutality from the state \\
& - death of close people• \\
& - Helpful family networks \\
& - Helpful community networks \\
& - Company from family and friends \\
& Reciprocal responsibility to society \\
& - Communal-based cultures \\
\hline Coping strategies &
\end{tabular}

\section{Supplementary Files}

This is a list of supplementary files associated with this preprint. Click to download.

- InterviewGuideUganda1.docx 